\title{
Compuestos Híbridos Lignina - Proteína - Quitosano como Potenciales Biomateriales para Aplicaciones Industriales
}

\author{
Mary Loprettia, Marianelly Esquivel ${ }^{\mathrm{b}}$, Sergio Madrigal ${ }^{\mathrm{b}}$, José Vega-Baudrit ${ }^{\mathrm{bc} *}$ y María Sibaja ${ }^{\mathrm{b}}$ \\ ${ }^{a}$ Facultad de Ciencias, Universidad de la República y Bioprocesos LATU, Uruguay \\ ${ }^{b}$ Laboratorio de Polímeros, Escuela de Química, Universidad Nacional, Costa Rica \\ ${ }^{c}$ Laboratorio Nacional de Nanotecnología LANOTEC-CeNAT-CONARE, Costa Rica. \\ *E-mail: jvegab@gmail.com
}

Recibido 1 de Julio de2014, Aceptado 30 de Septiembre 2014

\section{Resumen}

En este estudio se prepararon microcápsulas del conjugado lignina -proteína - quitosano. Con el objetivo de preparar "monómeros bien definidos (fenoles)", y utilizarlos en la síntesis de las microcápsulas, se realizó la fragmentación vía enzimática de diferentes ligninas. La producción de los fenoles se realizó en un reactor con una suspensión de la lignina a un $\mathrm{pH} 6.8$, en buffer de citrato $1 \mathrm{M}$, durante 6 horas a $37^{\circ} \mathrm{C}$ y utilizando enzimas de los cultivos de $G$. trabeum y $P$. chrysosporiumin.

En la preparación de las microcápsulas se empleó una disolución de quitosano en ácido acético, el cual fue mezclado con una disolución acuosa de lignina - proteína. El conjugado de lignina - proteína -quitosano se obtuvo mediante la interacción por enlaces de hidrógeno, producto de la disponibilidad de grupos amino e hidroxilo de los constituyentes. Esta interacción permitió el desarrollo de materiales estables tales como nanopartículas y biomembranas, las cuales poseen un potencial novedoso en aplicaciones en la industria médica y de la agronomía.

Palabras clave: Conjugados, lignina, quitosano, proteína, microcápsulas.

\section{Introducción}

El uso creciente de biopolímeros en diferentes aplicaciones industriales posiciona a la lignina como uno de los polímeros polifuncionales de mayor aplicación. Este potencial es altamente dependiente de las posibles modificaciones que se puedan realizar en la estructura química del polímero. Algunas aplicaciones industriales pueden ser implementadas mediante biopolímeros asociados utilizados en materiales compuestos híbridos. Recientemente polímeros como lignina, celulosa, quitina y quitosano se han aplicado en desarrollos de medicina y agroindustria, entre otros. En la Figura 1 se muestran algunos potenciales productos que se derivan de la lignina $[1,2]$.

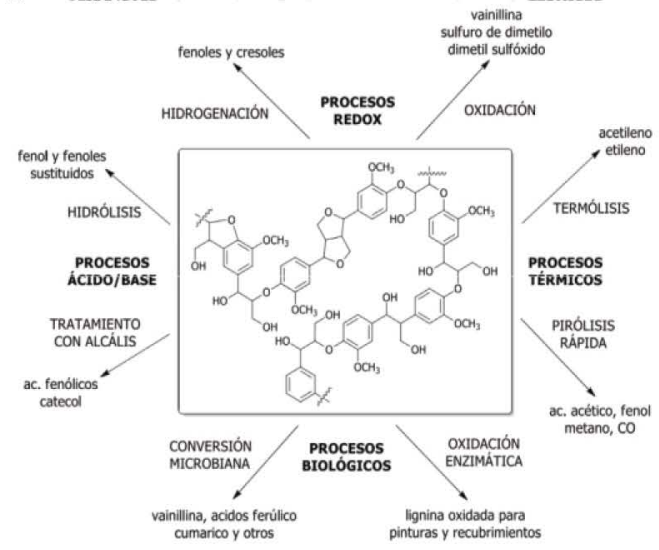

Figura 1. Esquema representativo de diferentes procesos de transformación de la lignina [2].
La lignina es un compuesto polifuncional fenólico que forma un complejo lignina - celulosa en madera y plantas. La extracción y las modificaciones de su estructura se pueden dar por vía química, tal como se realizan en procesos industriales, además de modificación por vía microbiológica o enzimática, las cuales son ampliamente estudiadas en proyectos de investigación y con menor desarrollo industrial.

Desde hace unos 10 años, químicos y bioquímicos han estudiado la biodegradación de ligninas. Se han empleado especies como la Coriolus versicolor, la Phanerochaete chrisosporium y la Phlebia radiata, y sus enzimas han sido estudiadas con mayor detalle. Las investigaciones se refieren a dos aspectos, al estudio analítico de los cambios producidos en las ligninas tratadas y a la búsqueda de un mecanismo común de acción para todas estas enzimas.

Desde el punto de vista químico, la lignina es un biopolímero muy resistente a la hidrólisis enzimática en comparación con otros biopolímeros. La incubación de ligninas con enzimas, muestra un incremento menor en los pesos moleculares de los oligómeros que los que se encuentran en las fermentaciones con microorganismos, posiblemente porque los pequeños fragmentos son eficientemente metabolizados y desaparecen quedando un sustrato remanente de gran peso molecular [3-5].

Una de las modificaciones químicas que se pueden 
realizar en la macromolécula de la lignina es la de la relación $\mathrm{O} 2 / \mathrm{C} 9$, la cual ofrece cambios muy significativos, y está asociado a procesos oxidativos [6]. Se pueden citar algunas modificaciones y rupturas de enlaces por los sistemas enzimáticos conocidos, estando muy lejos aún de conocer con exactitud el mecanismo real [7].

En general se observa que los grupos metoxilos así como las subestructuras beta-O-4 disminuyen marcadamente mientras que el contenido de oxígeno y grupos carboxilos aromáticos y alifáticos aumenta significativamente [8].

Se sugieren al menos tres modelos de degradación ocasionada por hongos basidiomicetes. En otros grupos de hongos como los pardos, no se conoce exactamente el mecanismo de degradación. Estos procesos son la ruptura oxidativa de la cadena propilo lateral entre carbonos alfa y beta para la formación de ácido benzoico; la ruptura del enlace aril éter y modificación de la cadena lateral, y la degradación del núcleo aromático por una apertura oxidativa del anillo [9]. Otros estudios evaluaron algunos de los posibles mecanismos en enzimas de hongos de pudrición blanca, como la lignina peroxidasa y la lacasa. Los estudios se realizaron con compuestos modelo de distinto tipo. En la Figura 2 se muestran los principales enlaces presentes en la macromolécula de la lignina y sus posibles tipos de ruptura de potencial interés comercial [2].

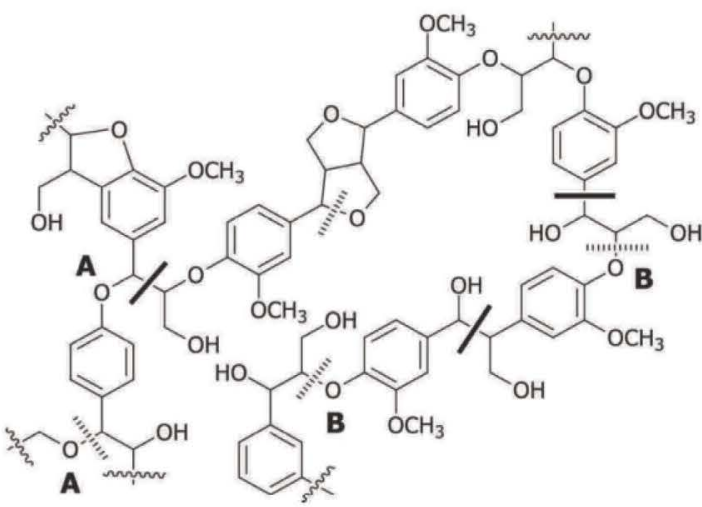

Figura 2. Principales enlaces presentes en la macromolécula de lignina, los posible tipos de enlace $\mathrm{C}$-O $\alpha$ aril éter (A) y ( $\beta$ ) aril éter y los posibles tipo de ruptura $\mathrm{C}-\mathrm{C}$ (barra oscura) y $\mathrm{C}-\mathrm{O}$ (barra punteada) [2].

Por otra parte, la quitina es un polisacárido natural encontrado en el exoesqueleto de crustáceos, artrópodos y hongos. El quitosano es un derivado desacetilado de la quitina con naturaleza policatiónica que promueve la formación de polielectrolitos similares a polianiones. En la Figura 3 se muestran las estructuras de la quitina y quitosano [10-15].

La capacidad de la lignina como polielectrolito permite unir por enlace y no por atrapamiento moléculas proteicas con diferentes funcionalidades, función de estructura o actividad enzimática. La aplicación en biomedicina, biotecnología e industria de alimentos no se ha optimizado todavía, siendo uno de los temas de estudio ya que permite una liberación controlada, termoestabilidad, protección a desnaturalización y recuperación para un uso seriado [16 y 17].

Otros beneficios asociados incluyen el control operacional, la flexibilidad en el diseño de reactores y la fácil recuperación del producto. El quitosano sirve como transportador para enzimas y proteínas.

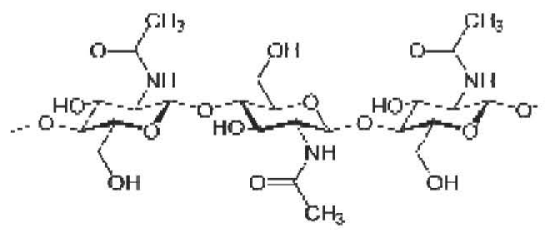

Lhitur Chitin-Deacetylase

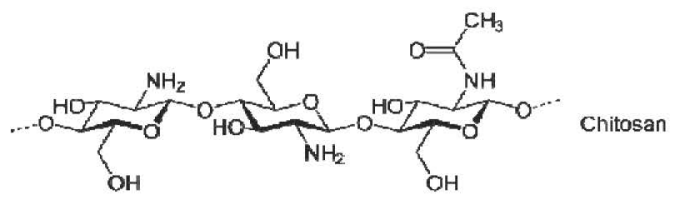

Figura 3. Estructura de quitina y quitosano [14].

En general, es inerte, hidrofílico, biocompatible, y por lo tanto atractivo en su aplicación. El complejo híbrido lignina -proteína se realiza por enlace covalente entre los grupos $\mathrm{OH}$ de la lignina y el $\mathrm{COOH}$ de la proteína. Este complejo se asocia con el quitosano en un sistema de microesferas que da mayor estabilidad y donde participan sus grupos amino [18]

El objetivo de este trabajo es obtener fragmentos de diferentes ligninas por vía enzimática, obteniendo unidades bien definidas, por medio de un control efectivo del mecanismo de biodegradación. Esto permitiría sintetizar cantidades significativas de monómeros y oligómeros fenólicos obtenidos a partir de recursos renovables. Asimismo, se pueden utilizar residuos de la industria de la celulosa, con lo cual se aumenta el valor agregado de los mismos en potenciales aplicaciones biomédicas y agronómicas de gran interés a nivel mundial.

\section{Parte experimental}

\section{Crecimiento de $G$ trabeum and $P$. chrysosporiumin.}

El crecimiento de los hongos se realizó en un medio líquido compuesto por $40 \mathrm{~g} / \mathrm{L}$ de maltosa, $10 \mathrm{~g} / \mathrm{L}$ de extracto de levadura y $1 \mathrm{~mL}$ de sales de Kirk en $250 \mathrm{cc}$ de medio de cultivo. Se inoculó el medio y fueron mantenidos los cultivos durante 6 días a $30^{\circ} \mathrm{C}$, sin agitación. El medio de conservación fue preparado por duplicado, en papa almidón-dextrosa-agar y en agarmalta, ambos mantenidos durante 7 días a $25^{\circ} \mathrm{C}$ y posteriormente guardados a $4^{\circ} \mathrm{C}$. 


\section{Producción de enzimas.}

Se prepararon $150 \mathrm{~mL}$ de medio con $10 \mathrm{~g} / \mathrm{L}$ de glucosa, $0.2 \mathrm{~g} / \mathrm{L}$ de extracto de levadura, $0.5 \mathrm{~g} / \mathrm{L}$ de tartrato de amonio y $1 \mathrm{~mL}$ de sales de Kirk, a pH 5. El medio fue esterilizado durante 15 minutos a $121^{\circ} \mathrm{C}$ e inoculado con $5 \mathrm{cc}$ del medio de crecimiento con cada hongo. Cada cultivo se mantuvo a $37^{\circ} \mathrm{C}$ durante 6 días y el sobrenadante fue analizado con respecto a la actividad enzimática.

\section{Análisis de la actividad enzimática.}

En el sobrenadante del cultivo se realizaron los siguientes ensayos de actividad enzimática. Las muestras fueron analizadas por triplicado. El equipo empleado fue un espectrofotómetro de la marca Shimadzu, modelo UV1800:

\section{Lignina Peroxidasa.}

Esta actividad fue determinada por el Método de Tien y Kirk. Se utilizó alcohol veratrílico $0.01 \mathrm{M}$ como sustrato en buffer de tartrato de sodio (0.1M, pH 3.0). La reacción fue iniciada agregando $4 \mathrm{mM}$ de $\mathrm{H}_{2} \mathrm{O}_{2}$ y monitorizada midiendo el incremento de absorbancia a $310 \mathrm{~nm}\left(\mathrm{e}_{\max }=9300 / \mathrm{M} \mathrm{cm}\right)$

\section{Lacasa.}

Esta actividad se determinó midiendo la oxidación de ABTS en buffer glicina- $\mathrm{HCl}(\mathrm{pH} 3.0$ ) a $420 \mathrm{~nm}$ $\left(\mathrm{e}_{\max }=36000 / \mathrm{M} . \mathrm{cm}\right) .2 \mathrm{ml}$ de solución de ABTS a pH 3 se incubaron con $0.1 \mathrm{ml}$ del sobrenadante del cultivo durante $1 \mathrm{~h}$ a $35^{\circ} \mathrm{C}$

\section{Demetilasas}

Se aplicó el método de medida sobre un compuesto modelo metoxilado. La reacción se siguió por medidas espectrofotométricas y la determinación del cambio en el espectro. Se tomaron $2 \mathrm{ml}$ de 3,4,5trimetoxibenzaldehído (Aldrich) $0.1 \mathrm{M}, \mathrm{pH} 4$, y se incubó con $0.1 \mathrm{ml}$ del sobrenadante del crecimiento fúngico a $30^{\circ} \mathrm{C}$. Se midió la disminución del sustrato por espectrofotometría UV.

\section{Determinación de proteínas.}

La determinación de proteínas se realizó por el método de la reacción de Folin. Las proteínas fueron pretratadas con ión cobre en solución alcalina, y luego los aminoácidos aromáticos presentes en la muestra redujeron al ácido fosfomolibdato fosfotúngstico presente en el reactivo de Folin. Se desarrolló un color azul, el cual fue cuantificado por espectrofotometría midiendo la absorbancia a $750 \mathrm{~nm}$ [19]. Las muestras fueron analizadas por triplicado. El equipo empleado fue un espectrofotómetro de la marca Shimadzu, modelo UV1800.

\section{Producción de "unidades fenólicas" de lignina.}

La producción de las unidades fenólicas se llevó a cabo en un sistema de hidrólisis enzimática, en reactor de $5 \mathrm{~L}$ con una solución de lignina Kraft al $1 \%$ m/v, pH 6.8 en buffer citrato $1 \mathrm{M}$. Esta reacción se realizó durante 6 hs a $37^{\circ} \mathrm{C}$ y las enzimas fueron obtenidas de un cultivo de $G$. trabeum y $P$. chrysosporiumin. Las enzimas fueron Ligperoxidasa $20 \mathrm{UE} / \mathrm{ml}$; Lacassa $10 \mathrm{UE} / \mathrm{ml}$ y Demetilasa 5UE/ml. Para el ensayo se utilizaron 100 UE de Ligperoxidasa 100UE de Lacassa y 50UE de Demetilasa. Luego de las 6 hs de acción enzimática, se centrifugó y se analizó el sobrenadante por espectrofotometría UV determinando las unidades fenólicas y derivados. Las muestras fueron analizadas por triplicado. El equipo empleado fue un espectrofotómetro de la marca Shimadzu, modelo UV-1800.

\section{Evaluación de la producción de fenoles.}

Se realizaron barridos espectrofotométricos entre 230 a $600 \mathrm{~nm}$ determinando los cambios en las lecturas por las oxidaciones producidas y se realizó una determinación de fenoles, utilizando una curva estándar de fenol. Las muestras fueron analizadas por triplicado. El equipo empleado fue un espectrofotómetro de la marca Shimadzu, modelo UV-1800.

\section{Preparación del conjugado Lignina- Proteína.}

Se prepararon $500 \mathrm{ml}$ de una solución $1 \%$ de oligómeros de lignina y $1 \%$ de proteína, en buffer citrato (1M) pH 4.2 Se agregó $0.1 \mathrm{ml} \mathrm{de} \mathrm{H}_{2} \mathrm{SO}_{4} 0.1 \mathrm{M}$, como catalizador . Para la fase dispersa se utilizó quitosano obtenido a través del Laboratorio de Polímeros POLIUNA de la Universidad Nacional (Costa Rica), obtenido por desacetilación alcalina a partir de exoesqueletos del camarón Heterocarpus vicarius.

Se preparó una solución de quitosano $1 \%(w / v)$ en ácido acético al $5 \%$ y se mezcló con una solución acuosa al $1 \%$ del conjugado Lignina - Proteína. Para la fase continua se usó vaselina con $0.1 \%(\mathrm{~m} / \mathrm{v})$ de Spam 80 . La mezcla de Lignina-Proteína -Quitosano fue incorporada lentamente por goteo dentro de la suspensión de vaselina para formar el compuesto híbrido con una concentración final de $5 \%(\mathrm{~m} / \mathrm{m}$ Quitosano a Lignina-Proteína). La solución fue mantenida bajo agitación a $(500 \mathrm{rpm})$ por una hora. Posteriormente se adicionó $20 \mathrm{ml}$ de glutaraldehído $10 \%(\mathrm{v} / \mathrm{v})$ y permaneció bajo agitación (500 rpm) hasta que las microcápsulas fueran decantadas. Para el lavado y recolección de las microesferas, se empleó un sistema de filtración con bomba de vacío. Se utilizó un kitasato de vidrio y embudo Büchner de porcelana con filtro de $0.75 \mu \mathrm{m}$ (Whatman). Se descartó el sobrenadante y se realizaron sucesivos lavados con éter de petróleo. A continuación se realizaron lavados con agua bidestilada Milli-Q para retirar restos del glutaraldehído, finalizando nuevamente con éter de petróleo. Las esferas se dejaron secar a temperatura ambiente. 


\section{Resultados y Discusión}

\section{Obtención de unidades de lignina.}

El crecimiento de los hongos se realizó en un medio líquido compuesto por maltosa, extracto de levadura y sales de Kirk. El medio de conservación fue preparado en papa almidón-dextrosa-agar y en agar-malta. El crecimiento de los hongos en ambos casos fue escaso. Esto se debe probablemente, a que el medio líquido empleado para su crecimiento no es el mismo medio natural que hay presente en el ecosistema.

\section{Actividad enzimática obtenida.}

En los filtrados de la producción de enzimas por cultivos mixtos de G. trabeum y $P$. chrysosporiumin se obtuvieron concentraciones de proteína de $0.8 \mathrm{mg} / \mathrm{mL}$. Las actividades enzimáticas obtenidas se muestran en la Tabla 1. En todos los casos se muestra actividad enzimática, siendo la mayor para la lignina peroxidasa.

Tabla 1. Actividad enzimática obtenida en Sistema líquido de $G$. trabeum y $P$ chrysosporium

\begin{tabular}{|c|c|c|}
\hline Actividad enzimática & G. trabeum y P. chrysosporium & UE/mL \\
\hline Lig peroxidasa & + & 20 \\
\hline Laccasa & + & 10 \\
\hline Demetilasa & + & 5 \\
\hline
\end{tabular}

\section{Estudio Espectrofotométrico.}

Los resultados observados en la Tabla 2 indicaron una extensa oxidación en la lignina tratada, y la obtención de productos de la despolimerización y oxidación.

Tabla 2. Absorbancia de ligninas sin tratamiento y solubilizadas por tratamiento enzimático con 100 UE de Lig-peroxidasa 100 UE de Lacassa y 50 UE de Demetilasa.

\begin{tabular}{|c|c|c|c|c|}
\hline \multirow{2}{*}{ Muestra } & \multicolumn{4}{|c|}{ Absorbancia ( \pm 0.05$)$} \\
\cline { 2 - 5 } & $280 \mathrm{~nm}$ & $310 \mathrm{~nm}$ & $353 \mathrm{~nm}$ & $375 \mathrm{~nm}$ \\
\hline Lignina sin tratamiento & 600.00 & 0.80 & & \\
\hline Lignina con tratamiento & 280.00 & 320.00 & 260.00 & 110.00 \\
\hline
\end{tabular}

En todos los ensayos donde el micelio creció, fue acompañado por el consumo de la fracción polimérica que disminuye y aparece en el sobrenadante siempre los mismos oligómeros y monómeros. Por lo tanto, los procesos de despolimerización oxidativa que ocurren en este sistema sugiere que el proceso se inicia por los enlaces interaromáticos, dando como producto oligómeros tipo fenólicos, seguido por la apertura del anillo, que generan fragmentos alifáticos con un incremento de los grupos carboxilo.

Las ligninas tratadas por este consorcio enzimático permiten obtener 3 fracciones de lignina de bajo PM que se han solubilizado. En todos los casos hay un incremento de la absorbancia en los productos de despolimerización y una disminución en el polímero de mayor tamaño.

\section{Producción del híbrido y microcápsulas.}

El compuesto híbrido Lignina-Proteína-Quitosano se desarrolló por interacciones de enlaces de hidrógeno por sus grupos amino e hidroxilos. Esta interacción permite el desarrollo de biomateriales estables, tales como nanopartículas y biomembranas.

\section{Conclusiones}

Estos estudios demuestran que es factible preparar consorcios enzimáticos capaces de modificar por despolimerización oxidativa un polifenol como la lignina dando siempre oligómeros fenólicos estables "unidades definidas" capaces de ser utilizadas para copolimerizar en compuestos híbridos.

Estas unidades dan la posibilidad de sintetizar diferentes tipos de edificaciones en blocks para la preparación de nuevos materiales poliméricos basados en recursos renovables constituidos por lignina.

Desde el presente resultado, parece ser posible trabajar con sistemas biológicos menos contaminantes y más específicos como son los consorcios enzimáticos. Si bien la parte principal del trabajo fue la despolimerización, la posibilidad de demetoxilar permitiría la incorporación del Fe contenido en péptidos y en hidrolasas, y la introducción de grupos carboxilo y otros

Las microcápsulas del compuesto híbrido obtenido de subproductos de la industria pesquera y la industria del papel permitirían agregar valor a estos subproductos con posibles aplicaciones en la industria de la biomedicina y el agro.

\section{Referencias}

1. Lopretti, M., Gandini, A., INNOTEC. 2012, 7, 59-63.

2. Chávez-Sifontes, M., Domine, M., Av. Cien. Ing. 2013, 4(4), 15-46.

3. Lopretti, M.; Carlomagno, M.; Gervacio, S.; Gandomenico, A. Biomass Energy Ind. 2004, 19511954.

4. Lopretti, M.; Santos, R.; López, G.; González, G. Biomass Energy Ind. 2004: 2026-2029.

5. Lopretti, M.; Gandini, A. Technical feassibility to produce modified phenols from lignocellulosic materials, 18th European Biomass Conference and Exhibition. 2010, 1519-1552.

6. Jellison , J.; Connoly, J.; Goodell, B.; Doyie, B. International Biodeterioration \& Biodegradation. 1997, 39, 165-179.

7. Agosin, E.; Blanchete, R. Appl. Environ.Microbiol. 1990, 11, 511-517.

8. Gandini, A. Initiation a le chemie eta le physic- 
chimic macromoleculaire. 2002, 13, 57 - 62 .

9. Enoki, A.; Itakura, S.; Tanaka, H. J. Biotechnol. 1997, $53,265-272$.

10. Yoshinori, K.; Hiraku, O.; Yoshiharu, M. Current Pharmaceutical Biotechnology. 2003, 4, 303-309.

11. Senay, A.; Akkus, Ç.; Nursevin, Ö. Enzyme and Microbial Technology. 2003, 32, 889-894.

12. Sanju, D.; Anil, K.; Singla, D.; Vivek Ranjan, S. AAPS PharmSciTech. 2004, 5,4, Article 67.

13. Dini, S.; Alexandridou, C.; Kiparissides,J. J. Microencapsulation. 2003, 20 (3), 375 - 385.

14. Meléndez, A., Vega-Baudrit, J., Sibaja, M., Madrigal, S., Camacho, M., Rev. Ib. Pol., 2013, 14 (5), 220-231.

15. Alvarado, R., Solera, F., Vega-Baudrit, J., Rev. Ib. Pol., 2014, 15 (3), 134-148.

16. Lopretti, M.; Damboriarena, A.; Ottati, C.; Olivera, A.; Sibaja, M.; Zamora, M.; Solano, V.; Barreiro, F. 16th European Biomass Conference and Exhibition. 2007, 722-1726.

17. Desai, H.; Park, J. J. Microencapsulation. 2005, 22, 4, 377-395.

18. Chetan, B.; Patel, M.; Vilar, G.; Gaikar, A. Separation Science and Technology. 2004, 39, 11, 2655-2675.

19. Lowry, O.II., Rosehrough, N.J., Farr, A., Randall, R.J., Biol. Chem. 1951, 193:265-275. 